\title{
A recent update of anticoagulant therapy on severe COVID-19 patients
}

\author{
Taofik RUSDIANA $1 *$ (D), Norisca Aliza PUTRIANA 1 (D), Patihul HUSNI 1 (D), \\ Mohammad Rizki AKBAR ${ }^{2}\left(\mathbb{D}\right.$, Takuya ARAKI ${ }^{3}\left(\mathbb{D}\right.$, Anas SUBARNAS ${ }^{4}$
}

1 Division of Drug Delivery and Disposition, Department of Pharmaceutics and Pharmaceutical Technology, Faculty of Pharmacy, Universitas Padjadjaran, Bandung, Indonesia

2 Department of Cardiology and Vascular Medicine, Faculty of Medicine, Universitas Padjadjaran, Bandung, Indonesia.

3 Department of Clinical Pharmacology, Gunma University Graduate School of Medicine, Maebashi, Gunma, Japan.

4 Department of Pharmacology and Clinical Pharmacy, Faculty of Pharmacy, Universitas Padjadjaran, Bandung, Indonesia.

* Corresponding Author. E-mail: t.rusdiana@unpad.ac.id (T.R.); Tel. +62-22-8428 8828 (3540).

Received: 19 May 2021 / Revised: 12 July 2021 / Accepted: 27 August 2021

\begin{abstract}
This paper aims to discuss how blood coagulation causes thromboembolic manifestations, including deep vein thrombosis (DVT), pulmonary embolism (PE), and other venous thrombosis events (VTE) and the possible mechanism and the effectiveness of using anticoagulant drugs in severely ill COVID-19 patients. This review is based on literature search through electronic databases of PubMed, UpToDate, Medline, Embase, International Pharmaceutical Abstract (IPA) and clinicaltrials.gov from December 2019 (since covid-19 emergence) to end of 2020. This review used keywords combination related to the association between covid-19 and blood coagulation (DVT, PE and other VTE), as well as clinical trials of anticoagulant drugs for the treatment of covid-19 patients. We summarized that thromboembolism incidence in severely symptomatic (ICU) patients ranges from 16.7 to $85 \%$. Furthermore, the main D-Dimer parameter had a significant difference between VTE (non-survival) and non-VTE (survival) patients. Meanwhile, the possible mechanism is the increased levels of complement and cascade components, including C1R, C1QC, C3b/C4b receptor 1 (CR1), C3, coagulation factors II, V, IX, and X, as well as reactive antiphospholipid antibodies affecting hypercoagulability, platelet activation, aggregation, and adhesion. Studies have shown the existence of thrombosis events in severe COVID-19 patients as well as the effectiveness of anticoagulants therapy in early prognosis, but the results of phase 3 clinical trials are still under investigation at several centers.
\end{abstract}

KEYWORDS: Anticoagulant; COVID-19; heparin; SARS-CoV-2; thromboembolism.

\section{INTRODUCTION}

Even though COVID-19 was initially regarded as a respiratory system disease, it still causes disorders in various body organs [1]. Till date, the effects of this virus are known, such as severe lung damage, and many deaths due to respiratory failure. However, there are reports that it causes other organs damage such as those of the cardiovascular system [1-4], liver [5,6], and acute kidney injury $[7,8]$ leading to fatal impacts. A study showed $14 \%$ (701 out of 5019) patients had a heart attack [9].

Meanwhile, the association between COVID-19 and thromboembolic disease or coagulation disorders in blood vessels including pulmonary embolism (PE), deep vein thrombosis (DVT) or venous thromboembolism (VTE) is rarely reported. Currently, in several countries, some health service facilities have started anticoagulant therapy, but the effectiveness reports are still limited and unclear. Therefore, this paper aims to provide information about the extent of COVID-19 impacts on blood vessels damage in the form of coagulation phenomena (thromboembolism or venous thrombosis), and its mechanism as well as anticoagulant therapy's effectiveness.

This review is based on a literature study available on PubMed, UpToDate, Medline, International Pharmaceutical Abstract (IPA) and clinicaltrials.gov databases using the following keyword combinations: COVID-19, SARS-CoV-2, anticoagulants, thromboembolism, and venous thrombosis ( VT), the mechanism of thromboembolism in covid-19 patients from December 2019 (start of the emergence of covid-19) to May 2021.

How to cite this article: Rusdiana T, Putriana NA, Husni P, Akbar MR, Araki T. A recent update of anticoagulant therapy on severe COVID-19 patients. J Res Pharm. 2021; 25(6): 807-814. 
In total, 78 articles (after the first screening of 134 records in all databases) were reviewed, but only 41 articles were included based on the inclusion and exclusion criteria. The inclusion criteria were: articles written in English, containing descriptions of thromboembolic phenomena in COVID-19 patients, the mechanism of sarcov-2 virus in causing thromboembolism, laboratory parameters in assessing blood clotting in COVID-19 patients, anticoagulant therapy in COVID-19 patients and clinical trials progress of anticoagulant drugs in COVID-19 patients. While the exclusion criteria in this review were thromboembolic events in patients before the patient suffered from COVID-19, anticoagulant therapy on patients which is not related to COVID-19 disease. Therefore, only those related to thromboembolism, biomarker mechanisms and parameters, and anticoagulant drug therapy in severe COVID-19 patients were analyzed further. The literature review and analysis flow chart is illustrated in Figure 1.

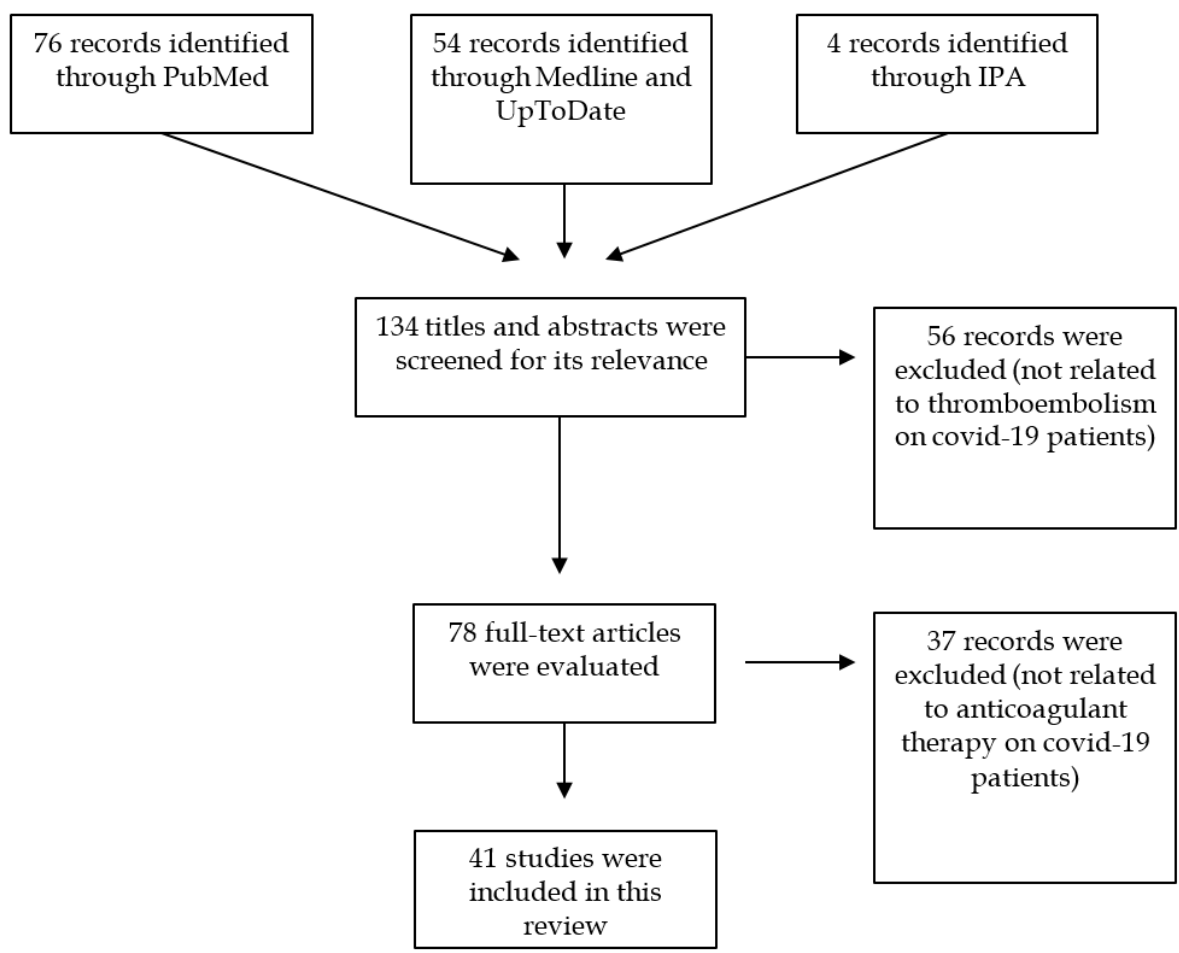

Figure 1. Flow chart of literature review and analysis based on inclusion and exclusion criteria.

\section{DISRUPTION OF THE BLOOD COAGULATION SYSTEM BY COVID-19}

Coronavirus (SARS-CoV-2) has been identified as a pathogen responsible for acute respiratory syndrome associated with severe inflammatory processes and pneumonia. Furthermore, the virus is thought to play a role in blood coagulation, and when it occurs in lung vessels, it can cause blockages, leading to pulmonary embolism. According to Vinayagam et al., SARS-Co-V-2 patients may experience a decrease in primary platelet production, an increase in platelet destruction, a decrease in circulating platelets which leads to an increase in thrombocytopenia which results in coagulation disorders. Endothelial dysfunction plays an important role in impaired coagulation by increasing thrombin formation and stopping fibrinolysis and ultimately leading to hypercoagulopathy. Furthermore, there will be activation of the complement system that leads to acute and chronic inflammation due to a storm of cytokines and chemokines that can cause multiorgan failure [10].

Initially, the relationship of COVID-19 to abnormal blood coagulation (thromboembolic events) was rarely mentioned until the study by Cui et al in China. It was stated that 20 of $81(25 \%)$ patients experienced VTE, and 8 died [11]. In Netherlands, the cumulative incidence of thromboembolic events was stated to reach $31 \%$, with $27 \%$ VTE and another 3.7\% experiencing arterial thrombosis [12], but Klok et al stated that it was $41 \%$ [13]. In Wuhan, China, Ren et al. reported $85 \%$ (41 out of 48 ICU patients) experienced lower limb DVT based on compression ultrasound examination [14]. Belen et al stated that the main pathogenesis begins with hypercoagulation and pulmonary intravascular coagulopathy (PIC), as well as recommended that early administration of anticoagulant therapy and thrombolytic drugs can provide a better prognosis [15]. Several 
studies on thromboembolism incidence in ICU patients can be seen in Table 1 which ranges from 9.3 to $85 \%$ $[13,14,16-25]$.

The laboratory parameters used to identify blood coagulation disorders were D-Dimer, fibrin/fibrinogen, prothrombin time (PT: the time taken for blood to clot) or can be expressed in INR (International Normalized Ratio: international standardization for measurement results of PT). In China, Han et al reported that the D-dimer, fibrin/fibrinogen degradation products (FDP), and fibrinogen (FIB) values in all SARS-CoV-2 cases were substantially higher compared to healthy controls. Moreover, the D-dimer and FDP levels were higher in severe than in mild infections. Prothrombin time activity (PT-act) was lower in the patients, while thrombin time in those with critical condition was also shorter than the value in the control group. This suggests that coagulation function in people with SARS-CoV-2 is significantly impaired when compared to healthy individuals, while D-dimer and FDP values' monitoring can help identify severe cases onset [26]. According to Shi et al based on meta-analysis of 6 studies involving 1379 patients, it was found that the D-dimer levels were significantly higher in non-survivals than survivals ( $\mathrm{SMD}=0.91,95 \% \mathrm{CI}=0.79$ 1.03). Therefore, elevated D-dimer levels is associated with an increased death risk [27]. Additional markers as thrombosis process predictors during hospitalization include platelets $>450 \times 10^{9} / \mathrm{L}$, C-reactive protein $(C R P)>100 \mathrm{mg} / \mathrm{L}$, and erythrocyte sedimentation rate (ESR) $>40 \mathrm{~mm} /$ hour. ESR, CRP, fibrinogen, ferritin, and procalcitonin levels were reported to be higher in those with thrombosis complications than in normal persons [28]. The differences in D-Dimer values in severely symptomatic COVID-19 (VTE/non-survival) and control (non-VTE/survival) patients from various studies are summarized in Table 2 [29-34].

Table 1. Incidence of venous thrombosis events (VTE) in intensive care unit (ICU) patients with moderate to severe symptoms of covid-19.

\begin{tabular}{llcc}
\hline \multicolumn{1}{c}{ Studies } & Countries & $\begin{array}{c}\text { Number of ICU } \\
\text { patients }\end{array}$ & $\begin{array}{c}\text { Percentage of patients } \\
\text { with VTE (\%) }\end{array}$ \\
\hline Cui et al. [11] & China & 81 & 25 \\
Klok et al. [12] & Netherlands & 184 & 27 \\
Klok et al. (update) [13] & Netherlands & 184 & 41 \\
Ren et al. [14] & China & 48 & 85 \\
Artifoni et al. [16] & France & 71 & 32 \\
Llitjos et al. [17] & France & 26 & 69 \\
Lodigiani et al. [18] & Italy & 48 & 16.7 \\
Maatman et al. [19] & USA & 109 & 28 \\
Middeldorp et al. [20] & Netherlands & 75 & 47 \\
Avruscio, et al. [21] & Italy & 41 & 75.6 \\
Demelo et al. [22] & Italy & 156 & 19.2 \\
Kerbikov et al. [23] & Rusia & 75 & 20 \\
Moll et al. [24] & USA & 210 & 9.3 \\
Trigonis et al. [25] & USA & 45 & 42.2 \\
\hline
\end{tabular}

Table 2. Comparison of D-Dimer level in COVID-19 patients that experienced venous thromboembolism (VTE) (VTE / non-survival) and non-VTE (survival).

\begin{tabular}{lccc}
\hline \multirow{2}{*}{ Studies } & \multicolumn{2}{c}{ D-Dimer value in COVID-19 patients $(\mathbf{m g} / \mathbf{L})^{*}$ p-value } \\
\cline { 2 - 3 } & VTE (Non-survival) & non-VTE (survival) & $<0.001$ \\
Han et al. [26] & $10.36 \pm 2.31$ & $0.26 \pm 0.18$ & $<0.001$ \\
Shi et al. [27] & $4.11 \pm 1.32$ & $0.72 \pm 0.34$ & $<0.001$ \\
Cheng et al. [29] & $5.3[1.3-21.0]$ & $0.6[0.3-1.1]$ & $<0.001$ \\
Sakka et al. [30] & $5.97 \pm 2.21$ & $0.72 \pm 0.12$ & $<0.001$ \\
Tang et al. [31] & $2.12(0.77-5.27)$ & $0.61(0.35-1.29)$ & $<0.001$ \\
Wu et al. [32] & $3.95(1.15$ to 10.96 & $0.49(0.31$ to 1.18$)$ & NA \\
Zhang et al. [33] & $\geq 2.0$ & $<2.0$ & $<0.001$ \\
Ahmet et al [34]** & $6.04 \pm 3.95$ & $1.02 \pm 1.75$ & \\
\hline *VTE/Non-survival means a severe symptomatic Covid-19 patient with thrombosis incidence and/or death; non-VTE \\
(survival) is someone with mild symptoms, without thrombosis and recovered. ** this study was grouped by “with Pulmonary \\
Embolism (PE) and wihout PE". P-values are based on different statistical methods, most of them are using The Mann- \\
Whitney U-test and the rest are using Student's t test.
\end{tabular}




\section{POSSIBLE MECHANISMS OF THROMBOSIS EVENTS IN COVID-19 PATIENTS}

Current reports support the strong prothrombotic diathesis concept in COVID-19, characterized by severe hypercoagulability rather than consumptive coagulopathy. Furthermore, SARS-CoV-2 infection affects the hemostatic pathway through different biological mechanisms at several levels. Recent observations based on autopsy results showed the presence of pulmonary vascular endotheliitis with a high in-situ microthrombus prevalence in alveolar capillaries consistent with thrombotic microangiopathy. COVID-19 coagulopathy has been described as an immune system-driven process, including cytokines and coagulation that work together to create a prothrombotic diathesis. Price et al reported the possible mechanisms for blood clot formation due to severe acute respiratory syndrome (SARS-CoV-2) attacks. When cells expressing the surface receptor angiotensin-converting enzyme (ACE-2) are infected, active replication and release of the virus causes the host to undergo pyroptosis (pro-inflammatory apoptosis), produce DAMPs (damageassociated molecular patterns), and activate oxidative stress. This leads to pro-inflammatory cytokines and chemokines release from nearby epithelium, endothelium, and alveolar macrophages. Subsequently, the proteins attract inflammatory cells to the infection site, thereby encouraging a pro-inflammatory feedback. Tissue factors usually hidden in the subendothelium are upregulated on platelets, leucocytes and endothelial cells (EC) during inflammation, leading to activation of the extrinsic and intrinsic coagulation pathways to produce thrombin. This product binds to protease-activating receptors (e.g. PAR-1) to promote fibrin formation from fibrinogen, platelet activation, subsequent clot stabilization, and further inflammation (Figure 2) [35]. Therefore, early DVT detection in COVID-19 patients allows more precise management by rapidly switching from standard thromboprophylaxis to definitive anticoagulant therapy [36].

Aid et al. investigated COVID-19 disease mechanisms in both experimental animals (Rhesus macaques) and humans, and showed that the virus caused inflammation and vascular thrombosis. It was found that SARS-CoV-2 caused an increased levels of several complement and cascade components, including C1R, $\mathrm{C} 1 \mathrm{QC}, \mathrm{C} 3 \mathrm{~b} / \mathrm{C} 4 \mathrm{~b}$ receptor 1 (CR1), C3, coagulation factors II, V, IX, and X. In addition, there was platelet activation, aggregation, and adhesion phenomenon including an increase in megakaryocyte cells [37]. The New England Journal of Medicine reported that the infection is associated with the development of reactive antiphospholipid antibodies (anti-IgA anticardiolipin, anti-B2 glycoprotein IgA, and IgG), which affects hypercoagulability [38].

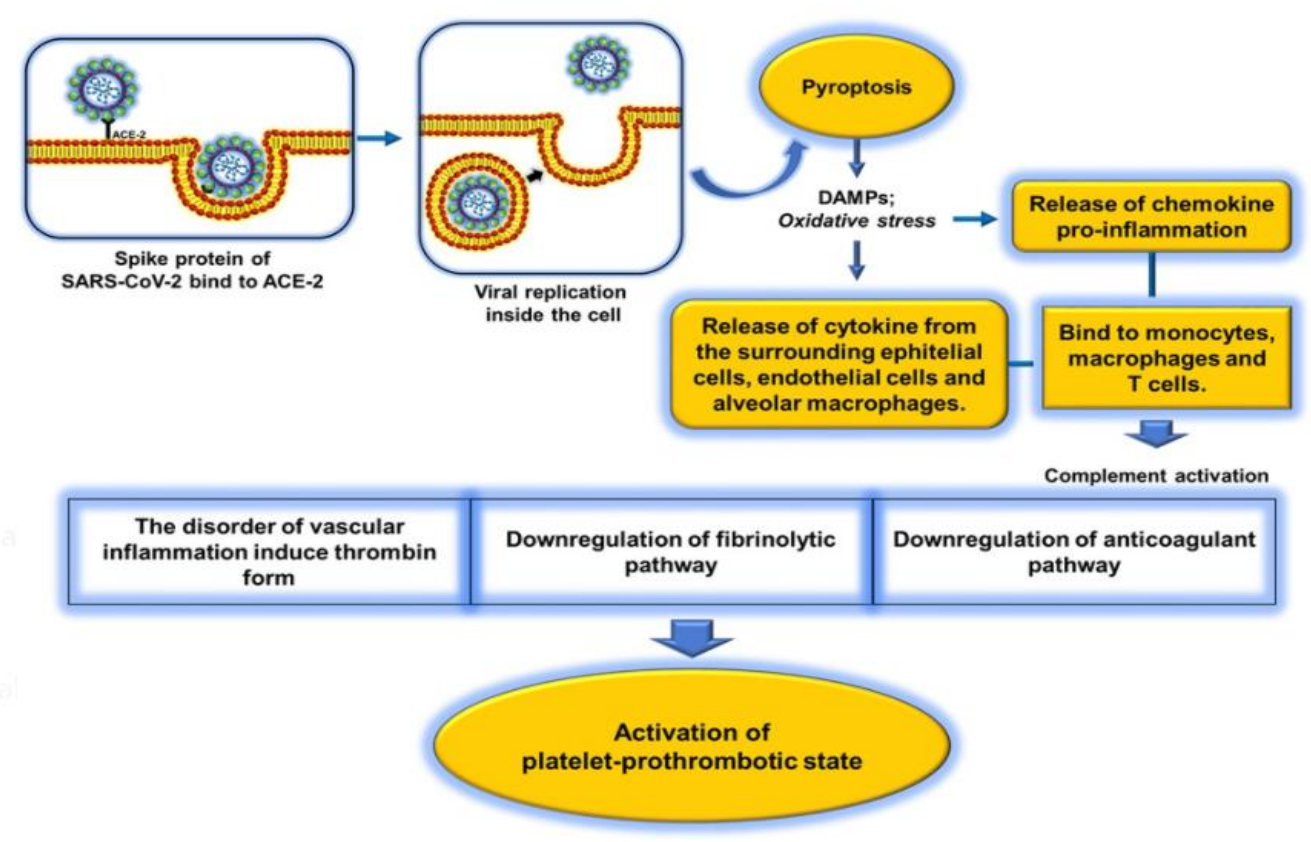

Figure 2. Mechanism of the possible thrombotic state due to sarcov-2 virus (modified from Price et al. [35]). 


\section{EFFECTIVENESS OF ANTICOAGULANT THERAPY IN SEVERE COVID-19 PATIENTS}

Some evidence showed that severe COVID-19 patients experienced coagulopathy complication in the form of disseminated intravascular coagulation (DIC), which is prothrombotic with a high risk of developing venous thromboembolism, and the D-Dimer can be used as blood clot disorders' parameter. Consequently, some experts provided recommendations for anticoagulants usage, which reflect the recognition of coagulation dysregulation in this case $[38,39]$. The effectiveness of heparin (particularly low molecular weight heparin, LMWH) in COVID-19 management has been recommended regarding the risk of developing DIC and venous thromboembolism. Also, prophylactic therapy with enoxaparin/heparin in more severe cases, or in people with D-dimer levels > six times above normal has been shown to reduce mortality. According to the latest version of guidelines published by the Iranian Ministry of Health, anticoagulants are given to the patients. All those hospitalized with COVID-19 diagnosis are given $40 \mathrm{mg}$ enoxaparin or 5000 units of heparin subcutaneously, twice or thrice daily. Mechanical prophylactic methods such as compressive stocking are recommended for those unable to use anticoagulants (due to absolute contraindications like intracranial hemorrhage and end-stage liver disease). However, the effectiveness of this anticoagulant therapy needs validation [40].

A single-center observational study involving 2,773 patients at Mount Sinai Hospital, America reported that out of the 786 receiving anticoagulant therapy (prophylactic dose, $\mathrm{LWMH}$ ), the mortality rate was $22.5 \%$, with an average 21-day survival, compared with $22.8 \%$ and 14-day in those untreated [41]. Furthermore, among the 395 critically ill and treated with mechanical ventilation, the rate was $29.1 \%$ in persons receiving anticoagulant and $62.7 \%$ in those that did not. There was no significant difference $(3.0 \%$ and $1.9 \%)$ in both groups with regards to bleeding complications (peptic ulcer, hematuria, melena, hemathesis, as well as intracranial, ocular and gastric hemorrhage). In the multivariate proportional hazards model, a longer duration of anticoagulant treatment was associated with a reduced death risk [41].

The European Society of Cardiology (ESC) has also recently developed an algorithm for anticoagulants usage. The administration needs to be considered for those at high risk of thrombosis, which are patients with dyspnea, respiratory rate $>24$ per minute, oxygen saturation $<90 \%$, elevation in C-reactive protein (CRP), Ddimer and fibrinogen levels. In ICU patients, the parenteral heparin drip administration protocol should be started immediately with 60-85 seconds target time for the activated partial thromboplastin (aPPT). For nonICU, subcutaneous $1 \mathrm{mg} / \mathrm{kg}$ body weight enoxaparin is recommended using the same protocol as the previous. In addition, bed side ultrasound (USG) modality is suggested for the assessment of deep vein thrombosis. When a positive result is obtained, anticoagulant therapy should be continued, but when negative, $40 \mathrm{mg}$ enoxaparin is recommended twice daily [38].

For supporting the evidence-based medicine, anticoagulant drugs therapy on covid-19 patients need to be investigated by phase 3 clinical trials. Furthermore, some of the potential anticoagulants including heparin (LMWH), enoxaparin, tinzaparin, dalteparin, fondaparinux, argatroban, apixaban, and rivaroxaban should considered to clinical trial tested. Till date, 54 anticoagulant drugs' clinical trials are registered on https://clinicaltrials.gov/ with a recruiting status and are already underway, but none has been completed. For example, the implementation of a clinical trial on 186 participants sponsored by Weill Medical College of Cornell University under the project name "IMPACT TRIAL". This aims to determine whether the therapeutic doses in the experimental group (subcutaneous, $1 \mathrm{mg} / \mathrm{kg}$ twice daily) can improve the 30-day mortality in COVID-19 patients compared with those receiving intermediate prophylaxis dose in the control (subcutaneous, $0.5 \mathrm{mg} / \mathrm{kg}$ once or twice daily, depending on creatinine clearance rates). Primary data from the results were estimated to be obtained around December 2020 and overall, this clinical trial will be completed in June 2021 [42]. Therefore, we should refere, consider and verify on the result from the clinical trial studies for further strong evidence. In Indonesia, there is no clinical trial for anticoagulants in COVID-19 patients registered at ClinicalTrials.gov, although it is possible that the therapy has been carried out in several hospitals.

\section{CONCLUSION}

Because COVID-19 patients experience thrombotic events as indicated by changes in blood clotting biochemical parameters such as D-Dimer, prothrombin time, increased levels of various coagulation factors and others, anticoagulant drugs can be given for prophylaxis (intermediate or long-term definitive therapy). Also, studies have shown the effectiveness of using anticoagulants in early prognosis. Therefore, to further prove the therapeutic effectiveness, the results of phase 3 clinical trials in various centers need to be considered and verified. 
Acknowledgements: The authors gratefully acknowledge the generous grant from The Rector of Universitas Padjadjaran that made this study possible with the grant number of 1959/UN6.3.1/PT.00/2021.

Author contributions: Concept - T.R., M.R.A., T.A.; Design - T.R., N.A.P., P.H.; Supervision - T.R., M.R.A., T.A., A.S.; Data Collection and/or Processing - T.R., N.A.P., P.H.; Analysis and/or Interpretation - T.R., N.A.P., P.H., M.R.A., T.A.; Literature Search - T.R., N.A.P., P.H.; Writing - T.R., N.A.P., P.H.; Critical Reviews - T.R., N.A.P., P.H., M.R.A., T.A, A.S.

Conflict of interest statement: The authors declared no conflict of interest.

\section{REFERENCES}

[1] Long B, Brady WJ, Koyfman A, Gottlieb M. Cardiovascular complications in COVID-19. Am J Emerg Med. 2020; 38(7): 1504-1507. [CrossRef]

[2] Bansal M. Cardiovascular disease and COVID-19. Diabetes Metab Syndr. 2020; 14(3): 247-250. [CrossRef]

[3] He XW, Lai JS, Cheng J, Wang MW, Liu YJ, Xiao ZC, Xu C, Li SS, Zeng HS. [Impact of complicated myocardial injury on the clinical outcome of severe or critically ill COVID-19 patients]. Zhonghua Xin Xue Guan Bing Za Zhi. 2020; 48(6): 456-460. [CrossRef]

[4] Tam CF, Cheung KS, Lam S, Wong A, Yung A, Sze M, Lam YM, Chan C, Tsang TC, Tsui M, Tse HF, Siu CW. Impact of Coronavirus Disease 2019 (COVID-19) Outbreak on ST-Segment-Elevation Myocardial Infarction Care in Hong Kong, China. Circ Cardiovasc Qual Outcomes. 2020; 13(4): e006631. [CrossRef]

[5] Lee IC, Huo TI, Huang YH. Gastrointestinal and liver manifestations in patients with COVID-19. J Chin Med Assoc. 2020; 83(6): 521-523. [CrossRef]

[6] Garrido I, Liberal R, Macedo G. Review article: COVID-19 and liver disease-what we know on 1st May 2020. Aliment Pharm Ther. 2020; 52(2): 267-275. [CrossRef]

[7] Adapa S, Chenna A, Balla M, Merugu GP, Koduri NM, Daggubati SR, Gayam V, Naramala S, Konala VM. COVID19 Pandemic Causing Acute Kidney Injury and Impact on Patients With Chronic Kidney Disease and Renal Transplantation. J Clin Med Res. 2020; 12(6): 352-361. [CrossRef]

[8] Gabarre P, Dumas G, Dupont T, Darmon M, Azoulay E, Zafrani L. Acute kidney injury in critically ill patients with COVID-19. Intensive Care Med. 2020; 46(7): 1339-1348. [CrossRef]

[9] Hayek SS, Brenner SK, Azam TU, Shadid HR, Anderson E, Berlin H, Pan M, Meloche C, Feroz R, O'Hayer P, Kaakati R, Bitar A, Padalia K, Perry D, Blakely P, Gupta S, Shaefi S, Srivastava A, Charytan DM, Bansal A, Mallappallil M, Melamed ML, Shehata AM, Sunderram J, Mathews KS, Sutherland AK, Nallamothu BK, Leaf DE. In-hospital cardiac arrest in critically ill patients with covid-19: multicenter cohort study. BMJ. 2020; 371(m3513): 1-10. [CrossRef]

[10] Vinayagam S, Sattu K. SARS-CoV-2 and coagulation disorders in different organs. Life Sci. 2020; 260: 118431-118431. [CrossRef]

[11] Cui S, Chen S, Li X, Liu S, Wang F. Prevalence of venous thromboembolism in patients with severe novel coronavirus pneumonia. J Thromb Haemost. 2020; 18(6): 1421-1424. [CrossRef]

[12] Klok FA, Kruip M, van der Meer NJM, Arbous MS, Gommers D, Kant KM, Kaptein FHJ, van Paassen J, Stals MAM, Huisman MV, Endeman H. Incidence of thrombotic complications in critically ill ICU patients with COVID-19. Thromb Res. 2020; 191: 145-147. [CrossRef]

[13] Klok FA, Kruip M, van der Meer NJM, Arbous MS, Gommers D, Kant KM, Kaptein FHJ, van Paassen J, Stals MAM, Huisman MV, Endeman H. Confirmation of the high cumulative incidence of thrombotic complications in critically ill ICU patients with COVID-19: An updated analysis. Thromb Res. 2020; 191: 148-150. [CrossRef]

[14] Ren B, Yan F, Deng Z, Zhang S, Xiao L, Wu M, Cai L. Extremely High Incidence of Lower Extremity Deep Venous Thrombosis in 48 Patients With Severe COVID-19 in Wuhan. Circulation. 2020; 142(2): 181-183. [CrossRef]

[15] Belen-Apak FB, Sarialioglu F. Pulmonary intravascular coagulation in COVID-19: possible pathogenesis and recommendations on anticoagulant/thrombolytic therapy. J Thromb Thrombolysis. 2020; 50(2): 278-280. [CrossRef]

[16] Artifoni M, Danic G, Gautier G, Gicquel P, Boutoille D, Raffi F, Neel A, Lecomte R. Systematic assessment of venous thromboembolism in COVID-19 patients receiving thromboprophylaxis: incidence and role of D-dimer as predictive factors. J Thromb Thrombolysis. 2020; 50(1): 211-216. [CrossRef] 
[17] Llitjos JF, Leclerc M, Chochois C, Monsallier JM, Ramakers M, Auvray M, Merouani K. High incidence of venous thromboembolic events in anticoagulated severe COVID-19 patients. J Thromb Haemost. 2020; 18(7): 1743-1746. [CrossRef]

[18] Lodigiani C, Iapichino G, Carenzo L, Cecconi M, Ferrazzi P, Sebastian T, Kucher N, Studt JD, Sacco C, Bertuzzi A, Sandri MT, Barco S, Humanitas C-TF. Venous and arterial thromboembolic complications in COVID-19 patients admitted to an academic hospital in Milan, Italy. Thromb Res. 2020; 191: 9-14. [CrossRef]

[19] Maatman TK, Jalali F, Feizpour C, Douglas A, McGuire SP, Kinnaman G, Hartwell JL, Maatman BT, Kreutz RP, Kapoor R, Rahman O, Zyromski NJ, Meagher AD. Routine Venous Thromboembolism Prophylaxis May Be Inadequate in the Hypercoagulable State of Severe Coronavirus Disease 2019. Crit Care Med. 2020; 48(9): E783-E790. [CrossRef]

[20] Middeldorp S, Coppens M, van Haaps TF, Foppen M, Vlaar AP, Muller MCA, Bouman CCS, Beenen LFM, Kootte RS, Heijmans J, Smits LP, Bonta PI, van Es N. Incidence of venous thromboembolism in hospitalized patients with COVID-19. J Thromb Haemost. 2020; 18(8): 1995-2002. [CrossRef]

[21] Avruscio G, Camporese G, Campello E, Bernardi E, Persona P, Passarella C, Noventa F, Cola M, Navalesi P, Cattelan A, Tiberio I, Boscolo A, Spiezia L, Simioni P, Group C-VS. COVID-19 and Venous Thromboembolism in Intensive Care or Medical Ward. Clin Transl Sci. 2020; 13(6): 1108-1114. [CrossRef]

[22] Demelo-Rodriguez P, Cervilla-Munoz E, Ordieres-Ortega L, Parra-Virto A, Toledano-Macias M, Toledo-Samaniego N, Garcia-Garcia A, Garcia-Fernandez-Bravo I, Ji Z, de-Miguel-Diez J, Alvarez-Sala-Walther LA, Del-Toro-Cervera J, Galeano-Valle F. Incidence of asymptomatic deep vein thrombosis in patients with COVID-19 pneumonia and elevated D-dimer levels. Thromb Res. 2020; 192: 23-26. [CrossRef]

[23] Kerbikov O, Orekhov P, Borskaya E, Nosenko N. High incidence of venous thrombosis in patients with moderateto-severe COVID-19. Int J Hematol. 2021; 113(3): 344-347. [CrossRef]

[24] Moll M, Zon RL, Sylvester KW, Chen EC, Cheng V, Connell NT, Fredenburgh LE, Baron RM, Cho MH, Woolley AE, Connors JM. VTE in ICU Patients With COVID-19. Chest. 2020; 158(5): 2130-2135. [CrossRef]

[25] Trigonis RA, Holt DB, Yuan R, Siddiqui AA, Craft MK, Khan BA, Kapoor R, Rahman O. Incidence of Venous Thromboembolism in Critically Ill Coronavirus Disease 2019 Patients Receiving Prophylactic Anticoagulation. Crit Care Med. 2020; 48(9): e805-e808. [CrossRef]

[26] Han H, Yang L, Liu R, Liu F, Wu KL, Li J, Liu XH, Zhu CL. Prominent changes in blood coagulation of patients with SARS-CoV-2 infection. Clin Chem Lab Med. 2020; 58(7): 1116-1120. [CrossRef]

[27] Shi L, Wang Y, Wang YD, Duan GC, Yang HY. D-dimer is associated with the risk of mortality in Coronavirus Disease 2019 patients. European review for medical and pharmacological sciences. 2020; 24(16): 8576-8579. [CrossRef]

[28] Al-Samkari H, Leaf RSK, Dzik WH, Carlson JCT, Fogerty AE, Waheed A, Goodarzi K, Bendapudi PK, Bornikova L, Gupta S, Leaf DE, Kuter DJ, Rosovsky RP. COVID-19 and coagulation: bleeding and thrombotic manifestations of SARS-CoV-2 infection. Blood. 2020; 136(4): 489-500. [CrossRef]

[29] Cheng A, Hu L, Wang Y, Huang L, Zhao L, Zhang C, Liu X, Xu R, Liu F, Li J, Ye D, Wang T, Lv Y, Liu Q. Diagnostic performance of initial blood urea nitrogen combined with D-dimer levels for predicting in-hospital mortality in COVID-19 patients. Int J Antimicrob Agents. 2020; 56(3): 106110. [CrossRef]

[30] Sakka M, Connors JM, Hékimian G, Martin-Toutain I, Crichi B, Colmegna I, Bonnefont-Rousselot D, Farge D, Frere C. Association between D-Dimer levels and mortality in patients with coronavirus disease 2019 (COVID-19): a systematic review and pooled analysis. J Med Vasc. 2020; 45(5): 268-274. [CrossRef]

[31] Tang N, Li D, Wang X, Sun Z. Abnormal coagulation parameters are associated with poor prognosis in patients with novel coronavirus pneumonia. J Thromb Haemost. 2020; 18(4): 844-847. [CrossRef]

[32] Wu C, Chen X, Cai Y, Xia J, Zhou X, Xu S, Huang H, Zhang L, Zhou X, Du C, Zhang Y, Song J, Wang S, Chao Y, Yang Z, Xu J, Zhou X, Chen D, Xiong W, Xu L, Zhou F, Jiang J, Bai C, Zheng J, Song Y. Risk Factors Associated With Acute Respiratory Distress Syndrome and Death in Patients With Coronavirus Disease 2019 Pneumonia in Wuhan, China. JAMA Intern Med. 2020; 180(7): 934-943. [CrossRef]

[33] Zhang L, Yan X, Fan Q, Liu H, Liu X, Liu Z, Zhang Z. D-dimer levels on admission to predict in-hospital mortality in patients with Covid-19. J Thromb Haemost. 2020; 18(6): 1324-1329. [CrossRef]

[34] Ahmet V, Nedim KA. D-dimer levels and acute pulmonary embolism development in COVID-19 patients. J Mind Med Sci. 2021; 8(1): 133-138. [CrossRef]

[35] Price LC, McCabe C, Garfield B, Wort SJ. Thrombosis and COVID-19 pneumonia: the clot thickens! Eur Respir J. 2020; 56(1): 2001608. [CrossRef] 
[36] Pizzolo F, Rigoni AM, De Marchi S, Friso S, Tinazzi E, Sartori G, Stefanoni F, Nalin F, Montagnana M, Pilotto S, Milella M, Azzini AM, Tacconelli E, Marchi G, Girelli D, Olivieri O, Martinelli N. Deep vein thrombosis in SARSCoV-2 pneumonia-affected patients within standard care units: Exploring a submerged portion of the iceberg. Thromb Res. 2020; 194: 216-219. [CrossRef]

[37] Aid M, Busman-Sahay K, Vidal SJ, Maliga Z, Bondoc S, Starke C, Terry M, Jacobson CA, Wrijil L, Ducat, , S. B, O.R. M, A.D., , Porto M, Pellegrini KL, Pino M, Hoang TN, Chandrashekar A, Patel S, Stephenson K, Bosinger SE, Andersen H, Lewis MG, Hecht JL, Sorger PK, Martinot AJ, Estes JD, Barouch DH. Vascular Disease and Thrombosis in SARS-CoV-2 Infected Rhesus Macaques. Cell. 2020; 183(5): 1354-1366.e13. [CrossRef]

[38] Rico-Mesa JS, Rosas D, Ahmadian-Tehrani A, White A, Anderson AS, Chilton R. The Role of Anticoagulation in COVID-19-Induced Hypercoagulability. Curr Cardiol Rep. 2020; 22(7): 53-53. [CrossRef]

[39] Kollias A, Kyriakoulis KG, Dimakakos E, Poulakou G, Stergiou GS, Syrigos K. Thromboembolic risk and anticoagulant therapy in COVID-19 patients: emerging evidence and call for action. Br J Haematol. 2020; 189(5): 846847. [CrossRef]

[40] Tang N, Bai H, Chen X, Gong JL, Li DJ, Sun ZY. Anticoagulant treatment is associated with decreased mortality in severe coronavirus disease 2019 patients with coagulopathy. Journal of Thrombosis and Haemostasis. 2020; 18(5): 1094-1099. [CrossRef]

[41] Paranjpe I, Fuster V, Lala A, Russak AJ, Glicksberg BS, Levin MA, Charney AW, Narula J, Fayad ZA, Bagiella E, Zhao S, Nadkarni GN. Association of Treatment Dose Anticoagulation With In-Hospital Survival Among Hospitalized Patients With COVID-19. Journal of the American College of Cardiology. 2020; 76(1): 122-124. [CrossRef]

[42] Anticoagulation in Critically Ill Patients With COVID-19 (The IMPACT Trial) (IMPACT). http:/ / clinicaltrials.gov/ct2/show/NCT04406389 (accessed on 10 October 2020). 